

Bert de Vries heads a project to restore an ancient water system near the town of Umm el-Jimal, Jordan.

as opposed to other arid nations, because of its geopolitical stability and support from the Jordanian government. Talozi spent this summer teaching officials and private-sector staff how to use modelling software from the Jordan Water Project, an international consortium of researchers based at Stanford University in California. The software takes into account an array of factors, including urban growth and water prices, to guide decisions about repairing or replacing water infrastructure and siting developments that might pollute groundwater, such as a refugee camp or a landfill. "Previously, there was software for the management of water according to physical parameters like precipitation, surface run-off and the efficiencies of the system," Talozi says, "but we wanted software that not only recognizes physical elements, but institutional behaviours that govern those systems, and considers economics."

$\mathrm{He}$ is also collaborating with scientists at the Massachusetts Institute of Technology in Cambridge on a low-pressure 'drip' irrigation technology that's thrifty with water and requires about half the energy of standard drip irrigation. The team has tested its technology in olive, citrus and pomegranate farms this summer, and plans a version in the next two years that will be powered by solar energy.

And the Helmholtz Centre for Environmental Research in Leipzig, Germany, is collaborating with the Jordanian government to test small, soil-filtered waste-treatment facilities that could lessen the leakage and inefficiencies seen in large plants, which can pollute nearby groundwater. Securing Jordan's water supply would also benefit Germany, says Roland Müller, a biotechnologist at Helmholtz. "The flow of Syrian refugees to Germany more or less started when camps in Jordan could not support them."

Talozi says the country might take its cue from ancient systems in Petra and Umm el-Jimal and store more rain - although these conduits alone cannot support today's population. Migrants are not the only cause of shortages, he says. "Jordanians want to go to the grocery store and buy apples and tomatoes and lettuce year round, not just eat wheat and barley."

But to de Vries, the resurrection of ruins in Umm el-Jimal serves as a hopeful reminder that people have survived harsh conditions by ingenuity. "As civilizations rotated through this land, one constant over time is the reuse and reliance of the water system," he says. "People in antiquity were not backwards; they were clever and thought of a technology we can revive." -

Travel for this story was supported by the Pulitzer Center on Crisis Reporting.

\title{
UK gender-equality scheme spreads across the world
}

The United States is set to trial a version that will also cover race and disability.

\section{BY ELIZABETH GIBNEY}

\section{A} programme that grades UK universities on gender equality in science is going global. Versions of the rating scheme have started up in the past two years in Australia and Ireland, and a small-scale pilot begins next month in the United States.

The British programme, Athena SWAN (Scientific Women's Academic Network), launched at ten universities in 2005 and has since spread to more than $140 \mathrm{UK}$ institutions. The voluntary scheme relies on universities supplying self-assessments to the Equality Challenge Unit, a non-profit organization that judges the institutions on their inclusiveness and equality in hiring, promoting and retaining female staff.

In addition to gender equality, the US project - called STEM Equity Achievement Change (SEA Change) - will assess inclusiveness with regards to race, ethnicity, sexual orientation, disability, socioeconomic status and other marginalized groups, says Shirley Malcom, who directs the education and human-resources programmes at the American Association for the Advancement of Science (AAAS) in Washington DC, which will oversee the project. The US effort will assess the experiences of both students and university staff. "We've had a lot of intervention programmes and it's not moving the needle," says Malcom. "We are exploring this strategy in order to try something that's better."

Around eight or nine currently unnamed US institutions will participate in the pilot scheme, which uses Athena SWAN as a model. Over a period of 12 to 18 months, individual departments or institutions as a whole will gather data on equality and identify problem areas. They are then expected to set plans and targets, such as boosting student diversity, closing pay gaps or making the campus climate more supportive. An AAAS panel will assess the submitted reviews and issue a bronze, silver or gold award accordingly.

Most higher-education institutions in 
- the United Kingdom now have at least one Athena SWAN rating. The scheme has been expanded in Britain to include the arts, humanities and social sciences, and has spread to Ireland and Australia, where the first 40 participating institutions will learn of their ratings in early 2018. There are also calls to launch similar schemes in India and Japan.

\section{FUNDING INCENTIVE}

A major reason for the scheme's rapid rise in the United Kingdom was its link to funding. In 2011 the UK government's chief medical officer, Sally Davies, made holding a silver award a requirement for receiving grants from a $£ 816$-million (US\$1.1-billion) pot of government biomedical funding. But the scheme spread well beyond the institutions competing for that funding. This was motivated in part by "moral pressure" but also because some staff thought that future funding decisions could become linked to such ratings, says Athene Donald, a physicist at the University of Cambridge, UK. Major funders such as the UK Research Councils recommend that institutions seek accreditation, but have not made it a requirement.

Success in the United States may depend on a major funder such as the US National Science Foundation requiring certification as a prerequisite for funding, says Curt Rice, who is head of the Norway government's Committee on Gender Balance and Diversity in Research.

Evaluations of the British programme have been positive. In a 2016 survey of UK academics, almost $90 \%$ of respondents who were aware of Athena SWAN felt that the scheme's initiatives had a positive impact on the work

“Institutions
struggling with
diversity and
inclusion likely
have causative
elements which
they are unable
to identify."
environment. Some institutions saw particular success. Between the University of Liverpool receiving a bronze award in 2013 and a silver in 2016, the proportion of women promoted to professor posts increased from $28 \%$ to $50 \%$. Other participating universities have made similar gains.

With thousands of public and private institutions in the United States, the pilot will have to adapt to the US higher-education system, says Malcom. Holding institutions accountable for every aspect of diversity will be impossible, she says, but examining data that they already collect will be a place to start. "My sense is that we really can't address the gender issues without looking at these other aspects" of diversity, she says. The AAAS hopes to expand the $\$ 200,000$ pilot scheme to universities across the United States, but will need more funding.

SEA Change has the potential to succeed, says Renee Horton, president of the National Society of Black Physicists. But she cautions that deep-rooted, prevailing and often unconscious prejudices that underlie inequality in the United States could make it difficult for universities to assess themselves, which means oversight by the AAAS would be essential. "Institutions struggling with diversity and inclusion likely have causative elements which they are unable to identify," she says.

\section{CORRECTION}

The Editorial 'Made of stone' (Nature 549, 5-6; 2017) appeared online with a poorly worded and offensive headline and standfirst. Taken together with some of the article's text, this implied that Nature supports retaining statues of historical figures whose work harmed others. This is not the case. As a result, the first sentence of the penultimate paragraph should have read "In cases where painful reminders are allowed to stand, they could be supplemented" instead of "Instead of removing painful reminders, perhaps these should be supplemented". Further discussion of this article can be found on page 160 and our apology appears online at go.nature.com/2xgh2j. 